\title{
Induction of Central Tolerance by Intrathymic Inoculation of Adenoviral Antigens into the Host Thymus Permits Long-term Gene Therapy in Gunn Rats
}

\author{
Yaron Ilan, ${ }^{\star}$ Preeti Attavar, ${ }^{\ddagger}$ Minoru Takahashi, ${ }^{\star}$ Anne Davidson, ${ }^{\ddagger}$ Marshall S. Horwitz, ${ }^{\ddagger \S}$ Jack Guida, ${ }^{\ddagger \S}$ \\ Namita Roy Chowdhury, ${ }^{*}$ and Jayanta Roy Chowdhury* \\ * Marion Bessin Liver Research Center, and Divisions of Gastroenterology and Hepatology and Rheumatology, Department of Medicine, \\ ${ }^{\ddagger}$ Department of Microbiology and Immunology, and ${ }^{\S}$ Seaver Institute of Human Genetics, Albert Einstein College of Medicine, Bronx, \\ New York 10461
}

\begin{abstract}
Recombinant adenoviruses are highly efficient at transferring foreign genes in vivo. However, duration of gene expression is limited by the host antiviral immune response which precludes expression upon viral readministration. We tested the feasibility of prolonging gene expression by induction of central tolerance to adenoviral antigens in bilirubin-UDP-glucuronosyltransferase-1 (BUGT ${ }_{1}$ )-deficient Gunn rats. Tolerance was induced by intraperitoneal injection of antilymphocyte serum, followed by intrathymic inoculation of one of the following: a recombinant adenovirus (Ad), adenovirus human UDP-glucuronosyltransferase (Ad-hBUGT ${ }_{1}$ ) carrying the hBUGT $_{1}$ gene; a protein extract of the same virus; or viral infected hepatocytes. Controls received intrathymic injections of normal saline. After $12 \mathrm{~d}$ all groups were injected intravenously with $5 \times 10^{9}$ pfu of either Ad-hBUGT ${ }_{1}$ or adenovirus $\beta$-galactosidase (Ad-LacZ) (expressing the Escherichia coli $\beta$-galactosidase [LacZ] gene). In all three groups of tolerized rats, hBUGT $_{1}$ was expressed in the liver after administration of Ad-hBUGT ${ }_{1}$, with glucuronidation of biliary bilirubin of above $95 \%$. Serum bilirubin levels decreased from 7.2 to $1.8 \mathrm{mg} / \mathrm{d} 1$ within $1 \mathrm{wk}$ and remained low for $7 \mathrm{wk}$. Similar findings were observed following repeat injections given on days $\mathbf{4 5}$ and 112 . In control rats serum bilirubin levels were reduced for only $4 \mathrm{wk}$, and viral readministration was ineffective. In all tolerized groups, but not in controls, there was a marked inhibition of appearance of neutralizing antibodies and cytotoxic lymphocytes against the recombinant adenovirus. Injection of wild type adenovirus-5 (Ad5) into the tolerized rats elicited a wild type-specific cytotoxic lymphocyte response. This is the first demonstration of Ad-directed long-term correction of an inherited metabolic disease following central tolerization with thymic antigen. (J. Clin. Invest. 1996. 98:2640-2647.) Key words: tolerance, intrathymic • recom-
\end{abstract}

Address correspondence to Jayanta Roy Chowdhury, M.D., Division of Gastroenterology and Liver Diseases, Department of Medicine, Albert Einstein College of Medicine, 1300 Morris Park Avenue, Bronx, NY 10461. Phone: 718-430-2265; FAX: 718-430-8975; E-mail: Chowdhur@AECOM.YU.edu

Received for publication 15 August 1996 and accepted in revised form 26 September 1996.

J. Clin. Invest.

(C) The American Society for Clinical Investigation, Inc. 0021-9738/96/12/2640/08 \$2.00

Volume 98, Number 11, December 1996, 2640-2647 binant adenovirus • gene therapy $\bullet$ UDP-glucuronosyltransferase $\bullet$ Crigler-Najjar syndrome type I

\section{Introduction}

Recombinant retroviruses and adenoviruses are being used by many investigators for somatic gene therapy. While retroviruses offer the advantage of integration into the host genome and have been used extensively for ex vivo gene transfer, they require cell division for integration, making them inconvenient for in vivo gene transfer into normally quiescent hepatocytes (1). In contrast, recombinant adenoviruses are highly efficient at transferring foreign genes into nondividing cells (2-3). Furthermore, studies in our laboratory and elsewhere show that recombinant adenovirus $5(\operatorname{Ad} 5)^{1}$ systemically administered to rodents, localizes and is preferentially expressed in the liver, probably because of the presence of specific receptors (4-5). Adenoviruses are nonenveloped, double stranded DNA viruses and their genome structure and biology offer a number of advantages for use as recombinant vectors in gene therapy. These viruses can be generated in high titers for in vivo gene therapy but do not integrate into the genome of infected cells (6-8). Several adenoviral vectors, constructed by deleting major parts of the viral genome, can shuttle more than $8 \mathrm{~kb}$ of heterologous sequences, providing a useful tool for gene therapy (7-8).

The early transcription region of the adenoviral genome (E1) controls viral gene expression and replication. First generation recombinant adenoviruses were generated by inserting the target gene in the E1 region, thus disrupting the region and rendering the virus replication defective $(4,6-8)$. However, despite the high efficiency of gene transfer by these vectors, expression of the foreign gene is transient because integration into the host cell genome is rare. Moreover, the viral proteins as well as the therapeutic gene product can induce both a cellular and humoral host response which precludes further gene expression after readministration of the virus (9-11). Because E1-deleted adenoviruses may express some viral proteins in vivo due to substitution of viral E1 functions by host tissue proteins, attempts were made to disable the virus further by introducing a mutation into the E2a region which results in the expression of a temperature-sensitive DNA binding protein (12-13). Mice injected with these second generation vectors

1. Abbreviations used in this paper: Ad, adenovirus; ALT, alanine aminotransferase; BUGT $_{1}$, UDP-glucuronosyltransferase; CTL, cytotoxic lymphocytes; $\mathrm{hBUGT}_{1}$, human UDP-glucuronosyltransferase; LacZ, $\beta$-galactosidase. 
had less liver and lung inflammation, but prolonged gene expression continued to be difficult to achieve in vivo (12-13). It is likely that viral antigens from the initial viral inoculum are processed and presented by host cells, thereby evoking an immune response. Therefore, deletion or mutation of viral genes, aimed at preventing expression of viral antigens after gene transfer, may not be fully effective in preventing the host immune reaction.

Intrathymic inoculation of foreign antigens including alloantigens and autoantigens, following transient depletion of host lymphocytes, has been shown to induce long lived tolerance to these antigens without the need for ongoing immunosuppression. Several mechanisms including clonal deletion or anergy of antigen specific $\mathrm{T}$ cells, suppression by regulatory cells, and/or secretion of factors that suppress the generation of antigen-specific effector cells are probably responsible for tolerance (14-17). We therefore wanted to evaluate whether the induction of central tolerance to the antigens present in the recombinant adenovirus could be used to abrogate the host immune response, thereby prolonging therapeutic gene expression.

For this study we chose the mutant Gunn rat as the recipient. Gunn rats lack hepatic uridine-diphospho-glucuronate glucuronosyltransferase (UGT) activity toward bilirubin and, as a consequence, do not excrete conjugated bilirubin in the bile (18). Gunn rats are an animal model of human CriglerNajjar syndrome type I. Because hepatic glucuronidation is essential for disposition of bilirubin, Gunn rats and patients with Crigler-Najjar syndrome type I have lifelong unconjugated hyperbilirubinemia, resulting in brain damage (19-21). CriglerNajjar syndrome is potentially lethal, and liver transplantation is the only definitive treatment (21). We introduced the gene for human bilirubin-UGT-1 (hBUGT $)$, the only enzyme that significantly contributes to bilirubin glucuronidation in human liver, into Gunn rats, using a recombinant adenoviral vector (5). The advantage of using Gunn rats for these experiments is that the BUGT expression can be evaluated by monitoring serum bilirubin levels (18-20). In addition, excretion of bilirubin glucuronides in bile provides unequivocal evidence of $\mathrm{hBUGT}_{1}$ expression in vivo. Our findings indicate that central tolerization markedly inhibits both the humoral and cellular host immune response, thereby permitting long-term gene expression by repeated administration of the virus. Furthermore, tolerance to the recombinant virus does not extend to wild type adenoviruses which express E1 proteins; therefore, the host defense against natural adenoviral infection is partly retained.

\section{Methods}

Animals. Inbred Gunn and congenic normal Wistar RHA rats were bred and maintained in the Special Animal Core of the Marion Bessin Liver Center of the Albert Einstein College of Medicine. The rats were maintained on standard laboratory chow and kept in 12-h light/dark cycles.

Plasmids. pJM17 was kindly provided by Dr. F.L. Graham, (McMaster University, Hamilton, Canada). Ad-LacZ virus was obtained through the courtesy of Dr. M. Imperiale, (University of Michigan, Ann Arbor, MI).

Generation of recombinant adenovirus. pRC/CMV (Invitrogen Corp., San Diego, CA) was partially digested with PvuII, and BglII linkers (Boehringer Mannheim Biochemicals, Indianapolis, IN) were inserted at position 1240. The $\mathrm{hBUGT}_{1}$ gene was cloned into pSVK3 (Promega Corp., Madison, WI) and the NotI-SpeI fragment was sub- cloned into $\mathrm{pRC} / \mathrm{CMV}$-BglII. The resulting expression cassette included the promoter and enhancer sequence for the immediate early gene of cytomegalovirus (CMV), the structural region of hBUGT and the polyadenylation signal from bovine growth hormone (pAdBglII-hBUGT ${ }_{1}$ ). The recombinant adenovirus, Ad-UDP-glucuronosyltransferase $\left(\mathrm{BUGT}_{1}\right)$ was generated by cotransfection of pAdBglIIhBUGT $_{1}$ and pJM17 into 293 cells, a human embryonic kidney cell line that supplies the product of the E1 region in trans, allowing the recombinant vectors to propagate (6). Briefly, 293 cells were seeded at $70-80 \%$ confluence in 24-well plates and transfected for $20 \mathrm{~h}$ with $250 \mu \mathrm{l}$ of transfection mixture containing $2 \mu \mathrm{g}$ of pAdBglII-h BUGT and $3 \mu \mathrm{g}$ of pJM17, mixed with $1 \mathrm{ml}$ of Optimedia containing $20 \mu \mathrm{l}$ of lipofectin (GIBCO-BRL, Gaithersburg, MD). After transfection, 293 cells were maintained in RPMI 1640 medium with $2 \%$ FCS until a cytopathic effect was observed. Ad-hBUGT ${ }_{1}$ was plaque purified and the integration of $\mathrm{hBUGT}_{1} \mathrm{cDNA}$ was confirmed by Southern blotting using viral DNA prepared by a modified Hirt procedure (6).

Large scale virus preparation. Recombinant adenoviruses were grown on 293 cells in suspension culture at a cell density of $5 \times 10^{5} / \mathrm{ml}$ using calcium-free essential medium (GIBCO-BRL) supplemented with $10 \%$ FCS. The cells $\left(1.6 \times 10^{9}\right)$, in 3 liters of medium, were infected by adding the supernatant from adenovirus infected 293 cells $\left(5 \times 10^{7}\right)$ that had been allowed to lyse completely. Cells were harvested $72 \mathrm{~h}$ after infection and resuspended in $10 \mathrm{mM}$ Tris- $\mathrm{HCl}(\mathrm{pH}$ 8.0). Recombinant adenovirus was purified from the cell lysate by two consecutive $\mathrm{CsCl}$ density gradient ultracentrifugations on preformed gradients, and stored in $30 \%$ glycerol at $-20^{\circ} \mathrm{C}$. Virus was dialyzed overnight at $4^{\circ} \mathrm{C}$ against an isotonic solution containing $135 \mathrm{mM}$ $\mathrm{NaCl}, 5 \mathrm{mM} \mathrm{KCl}, 1 \mathrm{mM} \mathrm{MgCl}, 10 \mathrm{mM}$ Tris- $\mathrm{HCl}, \mathrm{pH} 7.4$, and $10 \%$ glycerol, and sterilized by filtration through $0.45-\mu \mathrm{m}$ filters before use. The $\mathrm{CsCl}$ gradient supernatant, containing major adenoviral structural proteins, mainly fiber and hexon (22-23), was also collected and dialyzed, for inoculation into the thymus as described below.

Infection of rat hepatocytes with recombinant adenovirus in vitro. Gunn rat hepatocytes were obtained using collagenase perfusion as described (24), and cultured for $24 \mathrm{~h}$ on collagen coated plates using Chee medium supplemented by dexamethasone, insulin, glutamine, and $10 \%$ FCS (Eagle Medium, Dr. Chee's Modification, GIBCOBRL). The cultured cells were infected with the recombinant adenoviral preparation for $24 \mathrm{~h}$ at $100 \mathrm{pfu} / \mathrm{cell}$. Cells were then washed twice and were injected into the thymus as described below.

Injection of antilymphocyte serum and intrathymic inoculation. Antilymphocyte serum, $25 \mathrm{ml} / \mathrm{kg}$ body weight i.p. (ALS, Accurate Chemical and Scientific Corp, Westbury, NY), was injected on the day of intrathymic injection and $10 \mathrm{~d}$ later. For intrathymic injection, rats were anesthetized with ether and thymic lobes were exposed by a $2-\mathrm{cm}$ midline anterior neck incision. Both lobes were injected with either the recombinant virus, viral proteins, hepatocytes infected with the recombinant adenovirus or saline (control) in a volume of $100 \mu \mathrm{l}$. The incision was then closed with 3-0 nylon sutures. Rats receiving protein injections were inoculated with $100 \mu \mathrm{g}$ of the protein-containing fraction into each lobe.

Injection of rats with $A d-h B U G T_{1}$ and $A d-\beta$-galactosidase. Seven groups of Gunn rats, eight animals in each, were studied. Intrathymic injections were given as follows: group A received intrathymic Ad-hBUGT $1\left(1 \times 10^{8}\right.$ pfu in $0.1 \mathrm{ml}$ to each lobe $)$; six additional rats received the same protocol as group A but were not given any ALS; group B received viral proteins $(100 \mu \mathrm{g}$ in $100 \mu \mathrm{l})$; group C received adenovirus infected hepatocytes $\left(10^{6}\right.$ cells in $\left.0.1 \mathrm{ml}\right)$; and group D received normal saline (control). All rats were subsequently treated with three injections of Ad-hBUGT $1,5 \times 10^{9}$ pfu intravenously, administered $14 \mathrm{~d}$ after the intrathymic inoculations and subsequently at intervals determined by the time at which an increase of the serum bilirubin was observed, (on days 1, 45, and 112; Table I). Two further control groups were used: Group E received intrathymic Ad-hBUGT ${ }_{1}$ followed by one intravenous injection of Ad-hBUGT and then second and third injections of $\mathrm{Ad}-\beta$-galactosidase (B-gal). 


\begin{tabular}{|c|c|c|}
\hline Group & Intrathymic inoculation & Intravenous injection \\
\hline A & Ad-hBUGT $_{1}$ & Ad-hBUGT $_{1} \times 3$ \\
\hline $\mathrm{B}$ & Ad-hBUGT 1 soluble proteins & Ad-hBUGT $1 \times 3$ \\
\hline $\mathrm{C}$ & Ad-hBUGT infected hepatocytes & Ad-hBUGT ${ }_{1} \times 3$ \\
\hline $\mathrm{D}$ & Normal saline & Ad-hBUGT $1 \times 3$ \\
\hline $\mathrm{E}$ & Ad-hBUGT 1 & Ad-hBUGT $1 \times 1$, followed by Ad-LacZ $\times 2$. \\
\hline $\mathrm{F}$ & Ad-LacZ & Ad-LacZ $\times 3$ \\
\hline
\end{tabular}

Group F received an intrathymic inoculation of Ad-LacZ followed by three intravenous injections of Ad-LacZ.

\section{Evaluation of $\beta$-Gal and $h B U G T_{1}$ expression}

Assessment of $\beta$-Gal expression. Liver biopsies were performed every 3-4 wk on animals from groups $\mathrm{E}$ and $\mathrm{F}$, and specimens were frozen in Tissue Freezing Medium (Triangle Biomedical Sciences, Durham, NC), in a dry ice cooled methyl butane bath. Frozen Cryostat sections $(10 \mu \mathrm{m})$ were fixed for $5 \mathrm{~min}$ at room temperature in freshly prepared $1 \%$ glutaraldehyde in PBS. $\beta$-Gal activity was detected by immersing the section into 5 -bromo-4-chloro-3-indolyl- $\beta$-galactopyranoside (X-Gal) staining solution $\left(5 \mathrm{mM} \mathrm{K} \mathrm{K}_{4} \mathrm{FeCN}, 5 \mathrm{mM}\right.$ $\mathrm{K}_{3} \mathrm{FeCN}, 1 \mathrm{mM} \mathrm{MgCl}$, containing $1 \mathrm{mg}$ of X-Gal per ml) for $8-15 \mathrm{~h}$ at $37^{\circ} \mathrm{C}$. Sections were briefly counterstained with eosin, then dehydrated and mounted.

Determination of serum bilirubin levels. Serum bilirubin levels were measured according to Jendrasik and Grof (25) in all groups every 10-14 d throughout the study period.

Bile pigment analysis. For definitive demonstration of bilirubin glucuronidation in selected rats, bile was collected through a polyethylene bile duct cannula and bilirubin glucuronide excreted in bile was analyzed by HPLC using a $\mu$-Bondapak C-18 column (Millipore Corp., Waters Chromatography, Milford, MA) as described previously (26). In brief, bile duct cannulation was performed under ether anesthesia and animals were placed in restraining cages. After body temperature returned to normal, bile was collected on ice in the dark. The HPLC column was equilibrated with $50 \%$ methanol in $50 \mathrm{mM}$ ammonium acetate ( $\mathrm{pH} 4.5$ ). After injection of $0.2 \mathrm{ml}$ of a 1:1 mixture of bile and methanol, the pigments were eluted with a linear gradient of $50-100 \%$ methanol in ammonium acetate over $60 \mathrm{~min}$ at $1 \mathrm{ml} / \mathrm{min}$. Peaks were detected by absorbance at $436 \mathrm{~nm}$. Pigments were identified by retention time, using authentic pigments as standards, and quantified by integration of areas under the curves (26).

\section{Evaluation of immune tolerance}

Liver histology. For evaluation of the degree of hepatic inflammation, liver biopsies were performed every $3-4 \mathrm{wk}$ and stored in $10 \%$ formaldehyde. Paraffin sections were stained with hematoxylin-eosin according to standard procedures.

Serum alanine amino transferase levels. As a measure of hepatic inflammation, amino transferase (ALT) levels were quantified using a commercially available kit (Sigma Chemical Co., St. Louis, MO).

Adenoviral neutralizing antibodies. Rat antiadenovirus neutralizing serum antibodies were measured every 3-4 wk throughout the study. 293 cells were seeded at a concentration of $3 \times 10^{4} /$ well in $96-$ well plates, and cultured until $90 \%$ confluency. Ad-LacZ was diluted in cell culture medium to give $3 \times 10^{5} \mathrm{pfu} / 10 \mu \mathrm{l}$. Serum samples were heat inactivated at $55^{\circ} \mathrm{C}$ for $30 \mathrm{~min}$ and diluted in medium in twofold steps. $100 \mu \mathrm{l}$ of each serum dilution was mixed with $5 \times 10^{5}$ of the recombinant virus, incubated at $37^{\circ} \mathrm{C}$ for $90 \mathrm{~min}$, and applied to the nearly confluent 293 cells for $10-14 \mathrm{~h}$. The supernatant-containing serum and virus was then replaced by RPMI medium with $10 \%$ FCS for $18 \mathrm{~h}$. Cells were fixed and stained for $\beta$-Gal expression. In the absence of neutralizing antibodies all of the cells stained blue. The neu- tralizing antibody titer for each serum sample was reported as the highest dilution at which less than $25 \%$ of the cells stained blue.

Cytotoxic T lymphocyte assay. Two rats from each group were studied four times throughout the study on days 32, 64, 96, and 128. Inguinal and paraaortic lymph nodes were used for day 32 study, and subsequently spleens were removed from each of two rats at each time point. The organs were gently disrupted using a rubber policeman. Red blood cells were removed using lysis buffer containing $0.17 \mathrm{M}$ $\mathrm{NH}_{4} \mathrm{Cl}, \mathrm{pH} 7.4,(1 \mathrm{ml} / \mathrm{spleen}$ or 5-10 lymph nodes $)$, for $2 \mathrm{~min}$. Lymphocytes were spun down and plated at $5 \times 10^{7}$ cells per $5 \mathrm{ml}$ in RPMI medium with $10 \%$ FCS. Cells were then restimulated with the recombinant adenovirus Ad-hBUGT 1 (1-10 pfu) for 4-5 d. Ad-infected primary hepatocytes, obtained as described above, were used as target cells for the effector lymphocytes and were plated on collagencoated 6-well plates in Chee's medium $\left(2 \times 10^{6}\right.$ cells/well $)$. Stimulated effector cells were harvested, counted, and added to the primary hepatocyte cultures at a ratio of 50-100:1 and incubated at $37^{\circ} \mathrm{C}$ for $5 \mathrm{~h}$. Hepatic cell lysis was measured by collecting the medium and measuring alanine aminotransferase (ALT) levels using a commercially available kit (Sigma Chemical Co.) with the following modifications: the ratio between reagent and test medium was changed from 10:1 to $1: 1$, and the reaction time before the first spectrophotometric reading was $90 \mathrm{~s}$, followed by a reading every $30 \mathrm{~s}$ up to $5 \mathrm{~min}$. ALT levels were then calculated according to the manufacturers' formula and expressed in international units. Background ALT levels were determined by measurements of the ALT levels in the supernatants of dishes containing noninfected hepatocytes with and without adenovirus primed cytotoxic lymphocytes (CTLs), or adenovirally infected hepatocytes with the addition of CTLs from naive animals. CTL activity was expressed in IU of ALT averaged from 6 wells after subtraction of background levels.

Cellular immune response to wild type adenovirus. Two tolerized rats from each of groups $\mathrm{A}$ and $\mathrm{D}$ were injected with wild type adenovirus type 2, on days 133 and 149 after the third injection of the adenoviral vector. All rats were reexamined for bilirubin levels and CTL activity $4 \mathrm{~d}$ following each wild type viral injection.

Statistics. $P$ values were determined using the standard Student's $t$ test.

\section{Results}

Expression of $\beta$-Gal and $h B U G T_{1}$ gene after recombinant adenoviral injection into Gunn rats

Expression of $\beta$-Gal activity. Cryostat sections were prepared from liver specimens collected just before and $10 \mathrm{~d}$ after each Ad-LacZ injection from two rats from control group $\mathrm{F}$ (who had been injected only with Ad-LacZ), and from two rats from control group $\mathrm{E}$ (who had been initially tolerized with AdhBUGT $_{1}$ ). Nearly all hepatocytes from the group $F$ rats stained positive for $\beta$-Gal activity after the first injection, but only $5 \%$ of hepatocytes in liver tissues examined just before the second (day 42) or third (day 108) injections remained pos- 


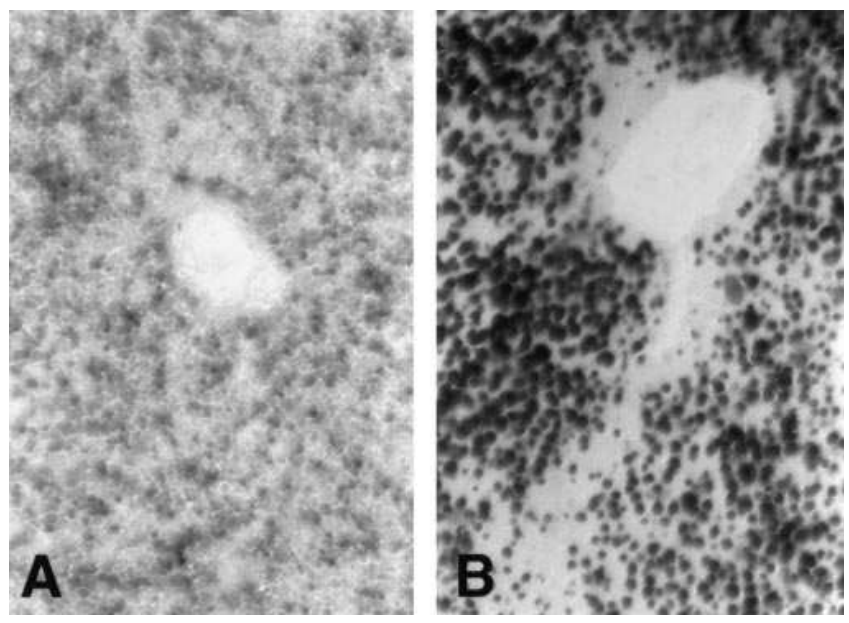

Figure 1. Effect of intrathymic tolerization on $\beta$-Gal expression Gunn rats: $\beta$-Gal staining of Gunn rat liver $5 \mathrm{~d}$ before $(A)$ and $10 \mathrm{~d}$ after $(B)$ the third injection of Ad-LacZ in Ad-LacZ tolerized rats from group $\mathrm{F}$.

itive. In both group $\mathrm{E}$ and group $\mathrm{F}$ animals, nearly all cells were positive $10 \mathrm{~d}$ following both the second and third injections of Ad-LacZ (Fig. 1). These results demonstrate that effective tolerance was achieved to the adenovirus using both the Ad-hBUGT 1 and the Ad-LacZ constructs, but that the duration of expression was transient.

Bile pigment analysis. HPLC analysis of bile collected from all experimental groups 3-4 wk after each injection showed excretion of bilirubin monoglucuronide and diglucuronide in bile. In groups $\mathrm{A}, \mathrm{B}$, and $\mathrm{C}$, the two glucuronides accounted for more than $95 \%$ of bile pigments, only $1.4 \%$ being unconjugated bilirubin (Fig. 2). This profile is similar to that seen in normal Wistar rats and remained unchanged throughout the study, demonstrating continued expression of the adenovirus construct at this time interval following each injection. In group $\mathrm{D}$, bile pigment analysis following the first injection showed a normal pattern of bilirubin glucuronide excretion, however, following the second and third injections, there was no significant excretion of conjugated bilirubin in the bile. This demonstrates that adenovirus expression could not be achieved following repeat injection in untolerized animals. As expected, Gunn rats injected with Ad-LacZ did not excrete bilirubin glucuronides in the bile. Chromatographic profiles of bile from these rats resembled those from untreated Gunn rats.

Serum bilirubin levels. Bilirubin levels were measured every 10-14 d. A marked decrease in bilirubin levels occurred after each Ad-hBUGT ${ }_{1}$ injection into tolerized Gunn rats (groups A-C), with levels reaching as low as 2.1, 1.2, and 1.1 $\mathrm{mg} / \mathrm{dl}$ after the first, second, and third injections, respectively (Fig. 3). Bilirubin levels remained low for 4-6 wk after each injection, and then increased gradually. In contrast, in untolerized Gunn rats (group D), Ad-hBUGT injection reduced serum bilirubin levels to $2.7 \mathrm{mg} / \mathrm{dl}$ for only $3 \mathrm{wk}$ and further injections had no effect on serum bilirubin concentrations. In rats receiving Ad-LacZ injections (group F) serum bilirubin levels were not significantly changed.

Liver histology. Liver biopsies taken from two rats in each group 24-72 h after each injection showed minimal or no periportal or lobular lymphocytic infiltration in groups $\mathrm{A}, \mathrm{B}$, and
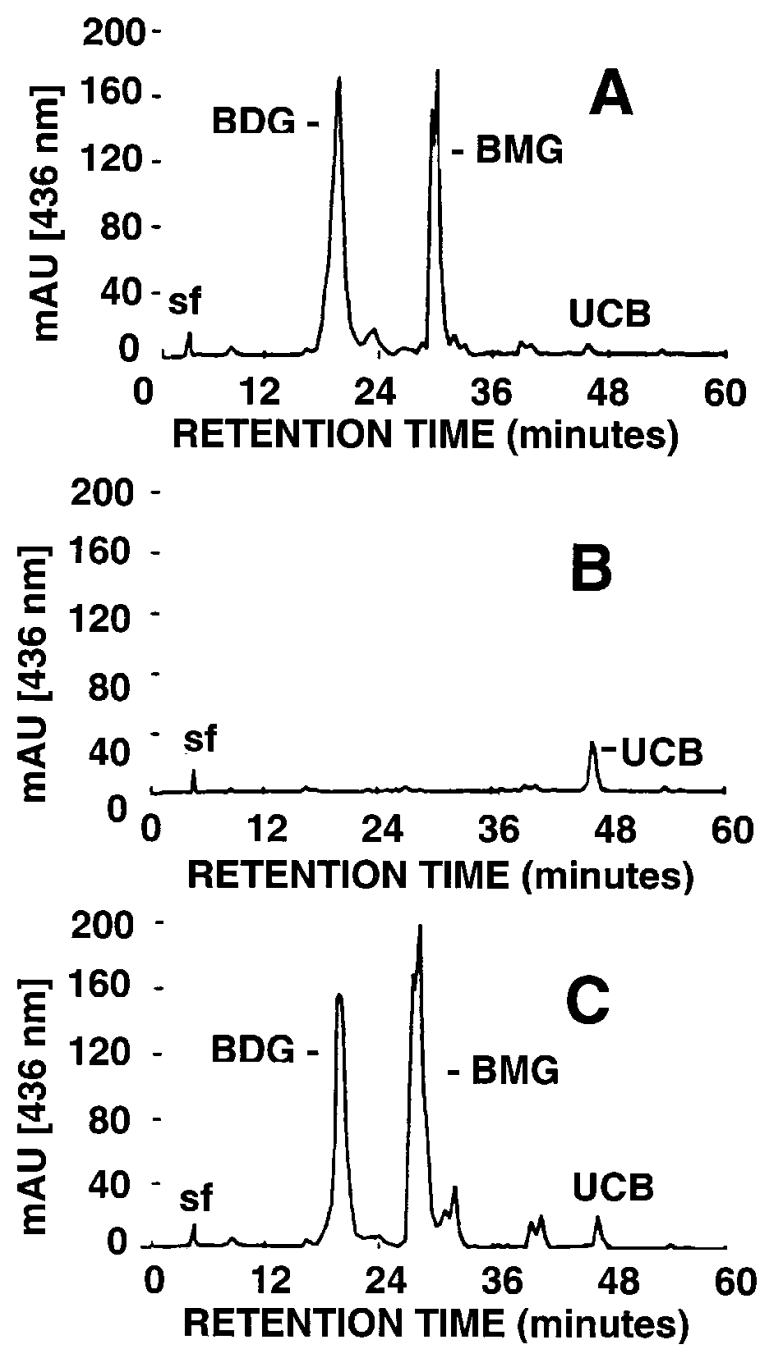

Figure 2. Effect of intrathymic tolerization on bile analysis in Gunn rats: HPLC of bile collected from tolerized Gunn rats from group A, after the third injection of $\mathrm{Ad}-\mathrm{hBUGT}_{1}(C)$ is compared to a normal Wistar rat $(A)$ and an untreated Gunn rat $(B)$. The first and second peaks represent bilirubin mono (BMG) and di-glucuronide (DBG), respectively, and the third band represents the unconjugated bilirubin (UCB).

C. In contrast, a more severe and increasing inflammatory reaction was observed in group $\mathrm{D}$ rats after the second and third injections (Fig. 4). Groups E and F showed similar results to those seen in group A.

Serum ALT levels. In the tolerized groups (groups A-C), serum ALT levels increased only minimally after each of the three injections (85-107 IU; normal levels before any manipulation were 65-76 IU). In group D rats, ALT levels increased to $124 \mathrm{IU}$ after the first injection, increasing to 182 and $194 \mathrm{IU}$ after the second and third injections, respectively $(P<0.005)$.

Neutralizing antibodies. After injection of Ad-hBUGT in $_{1}$ untolerized rats (group D), all rats developed high titer $(>1$ : 4000) antibodies during the first month. In contrast, in the tolerized rats (groups $\mathrm{A}, \mathrm{B}$, and $\mathrm{C}$ ), neutralizing antibodies were undetectable in $75 \%$ of the recipients. The remainder exhibited low titers of the antibody ( $<1: 16$; Fig. 5). Rats that developed the low titer antibodies had similar hypobilirubinemic re- 


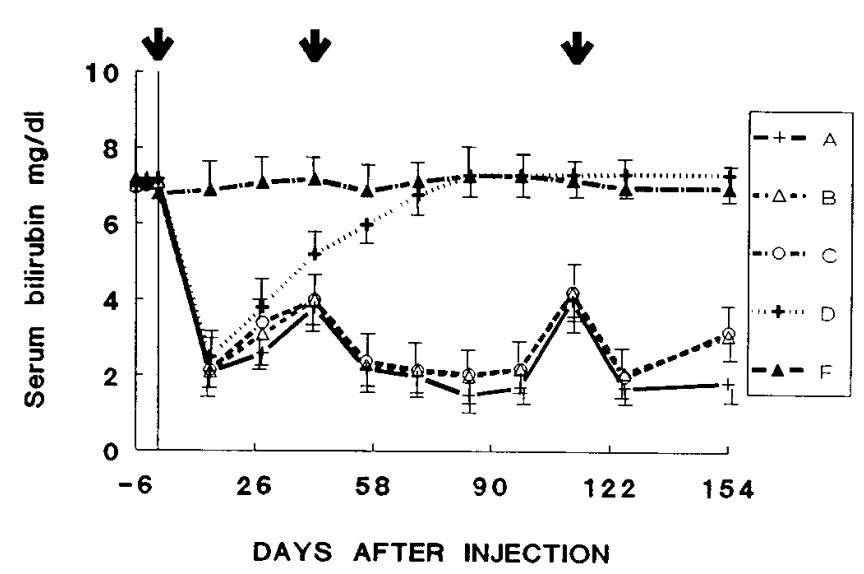

Figure 3. Effect of intrathymic tolerization on serum bilirubin levels in Gunn rats: Arrows indicate days of administration of recombinant adenovirus (see Table I). Rats from group E are not shown because they were used for $\beta$-Gal studies.

sponses to the second and third injections of Ad-hBUGT 1 as did the rats that had no detectable antibodies.

Cytotoxic T lymphocyte response. Cytotoxic $\mathrm{T}$ cells were tested against rat hepatocytes infected with adenoviruses four times throughout the study in groups A-D. Measurement of the amount of released ALT from the hepatocyte targets was used to quantify the CTL response. ALT levels remained below 40 IU in experiments using T cells from all tolerized recipients, compared to above $500 \mathrm{IU}$ in adult nontolerized rats (Fig. 6). The results shown are the mean of two rats examined in each group after subtraction of background levels.

Immune response of tolerized rats to wild type adenovirus. Two rats from the tolerized group A were injected with wild type adenovirus after the third Ad-hBUGT 1 injection. CTL tests showed that ALT concentrations in the media were 276 IU after the first injection of the wild type virus given on day 133, and 347 IU after the second injection given on day 149. These levels, although lower than those achieved in nontolerized rats, were much higher than the levels seen after the injection of the recombinant adenovirus in tolerized rats (Fig. 6).
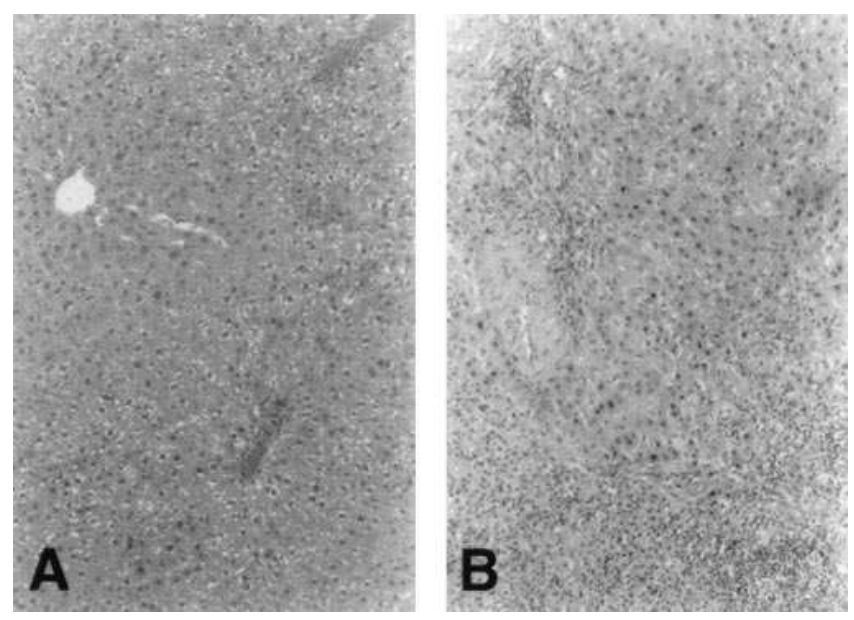

Figure 4. Intrathymic tolerization results in a diminished hepatic inflammatory response: Liver biopsy after the third injection of Ad$\mathrm{hBUGT}_{1}$ from a rat from experimental group A $(A)$ compared with a rat from control group $\mathrm{D}(B)$ showing a more marked intrahepatic inflammatory response.

Injection of the wild type virus did not affect the serum bilirubin levels in the treated rats.

Effect of antilymphocyte serum on induction of central tolerance. Six rats received a protocol identical to group A but did not receive antilymphocyte serum. The results regarding bilirubin levels, bile analysis, and immune response (including both antiadenovirus antibodies and CTL response) were similar to those of group A.

\section{Discussion}

Hepatic UGT activity toward bilirubin is essential for efficient biliary excretion of bilirubin. Inherited deficiency of bilirubin glucuronidation results in three grades of hyperbilirubinemia in humans, characterized by the accumulation of unconjugated bilirubin in the plasma (21). In the most severe form of the deficiency, a complete lack of bilirubin-UGT activity causes the

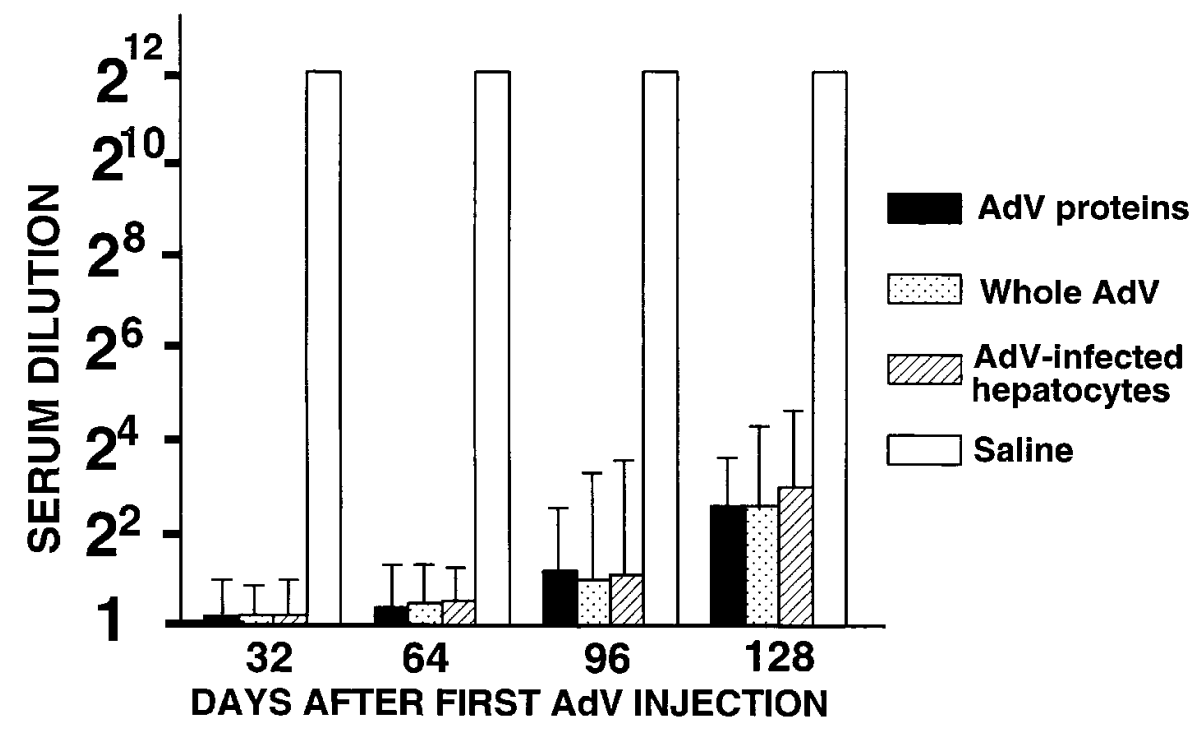

Figure 5. Intrathymic tolerization abrogates the humoral immune response to adenovirus: Levels of adenovirus neutralizing antibodies in tolerized (groups A, B, and C) and control rats (group D) displayed as the maximal serum dilution where $25 \%$ of hepatocytes were stained blue as described in Methods. Mean levels for each group were calculated from levels in antibody producing rats. 


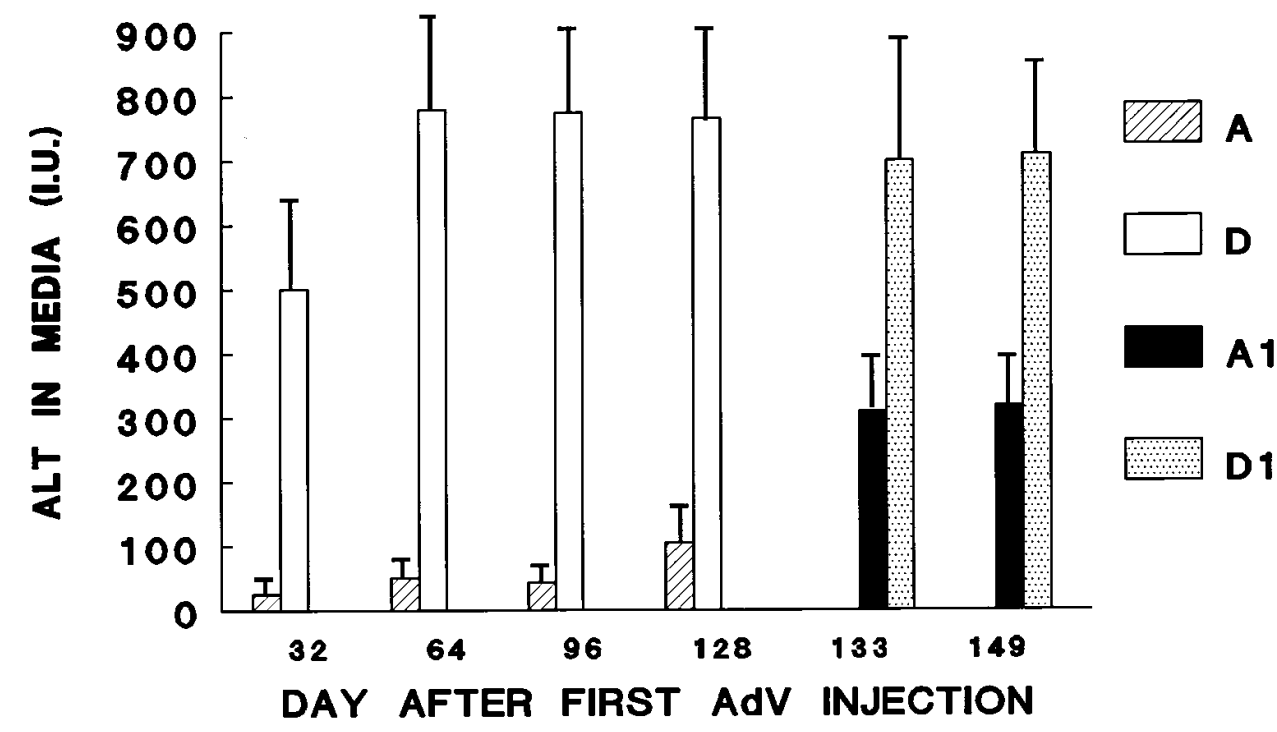

Figure 6. Effect of tolerization on cytotoxic lymphocyte (CTL) assay in tolerized and control Gunn rats. T cells were harvested after each injection from two rats in each group (A and D), and expressed as IU of ALT released from the hepatocytes. Two injections of wild type adenovirus were given to two rats from group A on days 133 and 149 (group A1) to study the effect of wild type adenovirus injection on CTL activity in tolerized and control rats. ALT levels were compared to levels in rats in group A injected with the recombinant virus, and to levels in two rats in group D injected with the wild type adenovirus on the same days (D1). potentially lethal disease, Crigler-Najjar syndrome type I (21). Although the longevity of patients with this syndrome has improved by the routine use of daily phototherapy, the patients always remain at the risk of kernicterus, and orthotopic liver transplantation is the only available definitive treatment. The Gunn rat is both a genetic and metabolic model of human Crigler-Najjar syndrome type I. In both cases, genetic lesions of the structural region of $\mathrm{BUGT}_{1}$ result in the loss of the functional enzyme (18-20). A major advantage of using the Gunn rat as a model for gene therapy is that the biliary excretion of bilirubin glucuronides is virtually absent, allowing direct and unequivocal quantification of the metabolic effect of gene therapy. In addition, serum bilirubin levels can be monitored to follow the duration of expression of the enzyme $(18,19)$.

The practical application of gene therapy for a metabolic disorder requires methods that allow long-term expression of the therapeutic gene product. Although retroviral vectors fulfill this requirement, their inability to integrate into nondividing cells make them inconvenient for gene transfer to the liver in vivo, as hepatocytes undergo mitosis infrequently (1). Our results show that recombinant adenoviral vectors are capable of transducing the great majority of hepatocytes in vivo permitting near complete correction of the metabolic defect in Gunn rats (5). However, as shown by other investigators, a limitation of adenoviral vectors is the relatively short duration of gene expression and the preclusion of transgene expression by the host immune response upon subsequent injections of virus (10-13). The data presented in this paper demonstrate that intrathymic injection of either recombinant adenovirus carrying the gene for $\mathrm{hBUGT}_{1}$, a mixture of recombinant viral proteins, or virally infected hepatocytes, tolerize rats to adenoviral antigens, thereby prolonging adenovirus mediated gene expression. More importantly, this approach shows for the first time that intrathymic tolerization allows long-term correction of a metabolic defect using an adenoviral delivery system.

The antiadenoviral response consists of both humoral and cell mediated components (9-11). The production of neutralizing antibodies to the adenovirus has been correlated with failure of gene expression when the virus is readministered after successful primary transduction (13-14). In addition, the loss of gene expression appears to be mediated in part by a cellular immune response against adenovirus transduced cells (9). The role of the $\mathrm{T}$ cell immune system in clearing adenovirus in infected rats was previously shown by studies using continuous dosage with cyclosporine, an immunosuppressive agent that inhibits IL-2 production, thereby suppressing the proliferation of activated T cells. Despite the development of antiadenovirus neutralizing antibodies, gene expression was significantly prolonged in cyclosporine-treated animals after adenovirusdirected gene transfer $(12-13,27)$. Use of knockout mice deficient in either the humoral or cellular arm of the immune system has shown conclusively that both arms contribute to the antiviral response and that prolonged gene expression following systemic administration of virus is only satisfactorily achieved with profound immunodeficiency such as is present in SCID mice $(10,27)$.

Intrathymic injection of foreign proteins has been shown to induce long-term immune unresponsiveness specifically toward these antigens without the need for ongoing immunosuppression (14-17, 28-30). Several different mechanisms may be involved in inducing immune tolerance by intrathymic inoculation. Newly produced $\mathrm{T}$ lymphocyte precursors must pass through the thymus at least once for positive selection (14-15). Ablation of the peripheral lymphocytes by ALS administration transiently depletes the peripheral pool of $\mathrm{T}$ cells to $10 \%$ of normal levels, thereby accelerating the traffic of the progenitor cells newly produced in the bone marrow through the thymus (14-15, 28-30). Within the thymus, the inoculated viral antigens are treated as "self," and the progenitor cells that strongly recognize these antigens may be clonally deleted or inactivated along with other self-reactive cells (28-29). Additional mechanisms involved in tolerization may include downregulation of the $\mathrm{T}$ cell response by regulatory cells (14), and/or secretion of factors that suppress the generation of antigen-specific effector cells $(14-15,30)$. Our study does not permit precise determination of which of these mechanisms were important in tolerance induction. However, our finding that omitting the antilymphocyte serum did not preclude tolerization suggests that thymic clonal deletion or inactivation does not entirely explain the tolerance induction in this system. Furthermore our ability to 
adoptively transfer the tolerance to naive animals, both in this model and in a transplantation model, suggests that other regulatory mechanisms have arisen in tolerized animals (unpublished data).

Our results are in accord with previous studies showing that intrathymic inoculation of either allogeneic cells or even allogeneic MHC-derived peptides can abrogate $\mathrm{T}$ cell-mediated transplantation rejection. Our results are different from those in a recent report that demonstrated that injection of adenovirus infected cells into the mouse thymus induced cellular, but not humoral tolerance (31). In that study, direct injection of the virus into the thymus resulted in production of a marked antiadenovial antibody response but no CTL response against the adenovirus (31). A possible explanation for the different findings may be that a significant degree of extravasation of the virus occurred during the intrathymic injection in the mouse, as indicated by viral expression in extrathymic tissues even when the virus was injected into the thymus only (31). The mouse study did not examine the effect of reinfection with the recombinant virus, therefore, the induction of central tolerance was not conclusively shown.

For clinical application of recombinant adenoviruses, the long-term consequences of inducing tolerance to adenoviruses must be considered. Adenoviral infection is common in humans. In the present study, injection of wild type adenoviruses into tolerized rats did not cause any detectable side effects. However, in contrast to rodent models where human adenoviruses do not complete the replication cycle, they are able to replicate in human subjects, where they are pathogenic. It is therefore of considerable interest that despite tolerization to the recombinant adenoviruses, the rats were able to mount a $T$ cell response after injection of the wild type adenovirus. This suggests that epitopes expressed by the E1 region of the adenovirus, which was disrupted in the recombinant virus, are also important antigenic epitopes in the cellular immune response against the virus (32-33). It is possible, therefore, that an anti-E1 immune response might protect tolerized subjects against infection by the wild type virus. Importantly, the administration of the wild type virus did not abolish the expression of the gene introduced via the recombinant adenovirus.

Crigler-Najjar syndrome and many other metabolic diseases are diagnosed early in childhood or even prenatally (34). Therefore, a functional thymus is available in these cases for several years, which could be potentially used to tolerize the subject to a useful recombinant adenovirus. It is unclear how long this tolerance would last and whether repeated intrathymic injections would be needed. Further understanding of the mechanisms by which tolerance is achieved in the rodent model will open the possibility of providing effective long-term gene therapy for inherited metabolic diseases using recombinant adenoviruses.

\section{Acknowledgments}

This work was supported in part by the following National Institutes of Health grants: ROI-DK 46057 (to J. Roy Chowdhury); RO1-DK 39137 (to N. Roy Chowdhury), and P30-DK 41296 (Liver Research Core Center), the Seaver Institute of Human Genetics of the Albert Einstein College of Medicine and the Core Cancer Research grant (M.S. Horwitz) and the MSTP grant (J. Guida). Y. Ilan was supported by the NIH Hepatology Training grant T32-DK07218.

\section{References}

1. Wilson, J.M., D.M. Jefferson, J. Roy Chowdhury, P.M. Novikoff, D.M. Johnston, and R.C. Mulligan. 1988. Retrovirus mediated transduction of adult hepatocytes. Proc. Natl. Acad. Sci. USA. 85:3014-3018.

2. Ali, M., N.R. Lemoine, and C.J.A. Ring. 1994. The use of DNA viruses as vectors for gene therapy. Gene Ther. 1:367-384.

3. Graham, F.L., and L. Prevec. 1991. Manipulation of adenovirus vectors. In Methods in Molecular Biology. E.J. Murray, editor. The Humana Press, Clifton, NJ. 109-128.

4. Jaffe, H.A., C. Danel, and G. Longenecker. 1992. Adenovirus-mediated in vivo gene transfer and expression in normal rat liver. Nat. Genet. 1:372-378.

5. Takahashi, M., K. Sengupta, N. Roy Chowdhury, and J. Roy Chowdhury. 1995. Prolonged expression of bilirubin UDP transferase I after adenovirus gene transfer into newborn Gunn rats. Hepatology. 22:453A.

6. Horwitz, M.S. Adenovirudae and their replication. 1990. In Virology. B.N. Fields, D.M. Knipe, and B.N. Fields, et al., editors. Raven Press, New York. 1679-1721.

7. Prevec, L., M. Schneider, K.L. Rosenthal, L.W. Belbeck, J.B. Derbyshire, and F.L. Graham. 1989. Use of human adenovirus-based vectors for antigen expression in animals. J. Gen. Virol. 70:429-434.

8. Bett, A.J., L. Prevec, and F.L. Graham. 1993. Packaging capacity and stability of human adenovirus type 5 vectors. J. Virol. 67:5911-5921.

9. Yang, Y., Q. Li, H.C.J. Ertl, and J.M. Wilson. 1995. Cellular and humoral immune responses to viral antigens create barriers to lung-directed gene therapy with recombinant adenoviruses. J. Virol. 67:2004-2015.

10. Dai, Y., E.M. Schwarz, D. Gu, W.W. Zhang, and N. Sarvetnick. 1995. Cellular and humoral immune responses to adenoviral vectors containing factor IX gene: tolerization of factor IX and vector antigens allows for long-term expression. Proc. Natl. Acad. Sci. USA. 92:1401-1405.

11. Armentano, D., A.R. Thompson, G. Darlington, and S.L.Woo. 1990. Expression of human factor IX in rabbit hepatocytes by retrovirus-mediated gene transfer: potential for gene therapy of human hemophilia B. Proc. Natl. Acad. Sci. USA. 87:6141-6145.

12. Yang, Y., F.A. Nunes, K. Berencsi, E. Gonczol, J.F. Engelhardt, and J.M. Wilson. 1994. Inactivation of E2a in recombinant adenoviruses improves the prospect for gene therapy in cystic fibrosis. Nat. Genet. 7:362-368.

13. Yang, Y., F.A. Nunes, K. Berenscsi, E.M. Furth, E. Gonczol, and J.M. Wilson. 1994. Cellular immunity to viral antigens limits E1-deleted adnoviruses for gene therapy. Proc. Natl. Acad. Sci. USA. 91:4407-4411.

14. Oluwole, S.F., M.X. Jin, N.C. Chowdhury, K. Engelstad, O.A. Ohajewke, and T. James. 1995. Induction of peripheral tolerance by intrathymic inoculation of soluble alloantigens: Evidence for the role of host antigen presenting cells and suppressor cell mechanism. Cell. Immunol. 162:33-41.

15. Markmann, J.F., J.S. Odorico, H. Bassirl, N. Desai, J.I. Kim, and C.F. Barker. 1993. Deletion of donor-reactive T lymphocytes after intrathymic inoculation with lymphoid cells. Transplantation (Baltimore). 55:871-877.

16. Ohazato, H., and A.P. Monaco. 1992. Induction of specific unresponsiveness to skin allografts by intrathymic donor specific splenocytes in antilymphocyte serum treated mice. Transplantation (Baltimore). 54:1090-1096.

17. Kappler, J.W., N. Roehm, and P. Marrack. 1987. T cell tolerance by clonal elimination in the thymus. Cell. 49:273-280.

18. Roy Chowdhury, J., N. Roy Chowdhury, C.N. Falancy, R.R. Tephly, and I.M. Arias, 1986. Isolation and characterization of multiple forms of rat liver UDP-glucuronide glucuronosyltransferase. Biochem. J. 233:827-837.

19. Roy Chowdhury, J., P.M. Novikoff, N. Roy Chowdhury, and A.B. Novikoff. 1985. Distribution of UDP-glucuronosyltransferase in rat tissue. Proc. Natl. Acad. Sci. USA. 82:2990-2994.

20. Bosma, P.J., N. Roy Chowdhury, B.G. Goldhoom, M.H. Hofker, T. Elferink, P.L.M. Jansen, and J. Roy Chowdhury. 1992. Sequence of exons and the flanking regions of human bilirubin UDP-glucuronosyltransferase gene complex and identification of a genetic mutation in a patient with Crigler-Najjar syndrome, type 1. Hepatology. 15:5:941-947.

21. Crigler, J.F., and V.A. Najjar. 1952. Congenital familial nonhemolytic jaundice with kernicterus. Pediatrics. 10:169-180.

22. Boulanger, P.A., and F. Puvion. 1973. Large scale preparation of soluble adenovirus hexon, penton and fiber antigens in highly purified form. Eur. J. Biochem. 39:37-42.

23. Everitt, E., B. Sundquist, U. Petterson, and L. Philipson. 1973. Structural proteins of adenoviruses: Isolation and topography of low molecular weight antigens from the virion of adenovirus type 2. Virology. 52:130-147.

24. Seglen, P.O. Preparation of isolated rat liver cells. Methods Cell Biol. 1976.13:29-83

25. Trotman, B.W., J. Roy Chowdhury, and G.D. Wirt. 1982. Azodipyroles of unconjugated and conjugated bilirubin using diazotized ethyl anthranilate in dimethyl sulfoxide. Anal. Biochem. 121:175-180.

26. Roy Chowdhury, J., N. Roy Chowdhury, G. Wu, R. Shouval, and I. Arias. 1981. Bilirubin mono and diglucoronide formation by human liver in vitro: Assay by high pressure liquid chromatography. Hepatology. 1:622-627.

27. Kass-Eisler, A., E. Falck-Pederson, D.H. Elfenbein, M. Alvira, P.M Buttrick, and L.A. Leinwand. 1994. The impact of development stage, route of administration and the immune system on adenovirus-mediated gene transfer. 
Gene Ther. 1:395-402.

28. Kisielo, P., H. Bluthmann, and U.D. Staerz. 1988. Tolerance in T cell receptor transgenic mice involves deletion of nonmature CD4+8+ thymocytes. Nature (Lond.). 333:742-746.

29. Posselt, A.M., C.F. Barker, and J.E. Tomaszewski. 1990. Induction of donor specific unresponsiveness by intrathymic islet transplantation. Science (Wash. DC). 249:1293-1295.

30. Odorico, J.S., T. O'Conor, L. Campos, C.F. Barker, A.M. Posselt, and A. Naji. 1993. Examination of the mechanisms responsible for tolerance induction after intrathymic inoculation of allogeneic bone marrow. Ann. Surg. 218: 525-531.

31. DeMatteo, R.P., S. Raper, M. Ahn, K.J. Fisher, C. Burke, A. Radu, G.
Widera, B. Claytor, C. Barker, and J.F. Markmann. 1995. Gene transfer to the thymus. Ann. Surg. 222:229-242.

32. Berk, A.J. 1986. Adenovirus promoters and E I A transactivation. Am. Rev. Genet. 20:4579-4585.

33. Efrat, S., G. Fejer, M. Brownlee, and M. Horwitz. 1995. Prolonged survival of pancreatic islet allograft mediated by adenovirus immunoregulatory transgenes. Proc. Natl. Acad. Sci. USA. 92:6947-6951.

34. Sengupta, K., S. Gantla, V.R. Bommineni, P. Attavar, R. Hughes-Benzie, P.J. Bosma, J. Roy Chowdhury, N. Roy Chowdhury. 1994. Prenatal identification of Crigler-Najjar syndrome type 1 genotype by analysis of chronic villus sample DNA. Hepatology. 13:320A. 